\title{
Clinical and virological characteristics of hospitalised COVID-19 patients in a German tertiary care centre during the first wave of the SARS-CoV-2 pandemic: a prospective observational study
}

\author{
Charlotte Thibeault ${ }^{1}$ - Barbara Mühlemann ${ }^{2,3}$ - Elisa T. Helbig ${ }^{1}$ - Mirja Mittermaier ${ }^{1,4}$ - Tilman Lingscheid ${ }^{1}$. \\ Pinkus Tober-Lau ${ }^{1}$ - Lil A. Meyer-Arndt ${ }^{5,6}$. Leonie Meiners ${ }^{2,3}$. Paula Stubbemann ${ }^{1}$ - Sascha S. Haenel ${ }^{1}$. \\ Laure Bosquillon de Jarcy ${ }^{1,2,3} \cdot$ Lena Lippert $^{1} \cdot$ Moritz Pfeiffer $^{1} \cdot$ Miriam S. Stegemann ${ }^{1} \cdot$ Robert Roehle $^{4,7}$. \\ Janine Wiebach $^{4,7}$. Stefan Hippenstiel ${ }^{1}$. Thomas Zoller ${ }^{1}$. Holger Müller-Redetzky ${ }^{1}$ - Alexander Uhrig ${ }^{1}$. \\ Felix Balzer $^{8} \cdot$ Christof von Kalle $^{4} \cdot$ Norbert Suttorp $^{1,9} \cdot$ Terry C. Jones $^{2,3,10} \cdot$ Christian Drosten $^{2,3}$. \\ Martin Witzenrath $^{1,9} \cdot$ Leif E. Sander $^{1} \cdot$ Pa-COVID Study Group · Victor M. Corman ${ }^{2,3} \cdot$ Florian Kurth $^{1,11,12}$ (I)
}

Received: 21 December 2020 / Accepted: 23 February 2021 / Published online: 22 April 2021

(c) The Author(s) 2021

\begin{abstract}
Purpose Adequate patient allocation is pivotal for optimal resource management in strained healthcare systems, and requires detailed knowledge of clinical and virological disease trajectories. The purpose of this work was to identify risk factors associated with need for invasive mechanical ventilation (IMV), to analyse viral kinetics in patients with and without IMV and to provide a comprehensive description of clinical course.

Methods A cohort of 168 hospitalised adult COVID-19 patients enrolled in a prospective observational study at a large European tertiary care centre was analysed.

Results Forty-four per cent (71/161) of patients required invasive mechanical ventilation (IMV). Shorter duration of symptoms before admission (aOR 1.22 per day less, 95\% CI 1.10-1.37, $p<0.01$ ) and history of hypertension (aOR 5.55, 95\% CI 2.00-16.82, $p<0.01$ ) were associated with need for IMV. Patients on IMV had higher maximal concentrations, slower decline rates, and longer shedding of SARS-CoV-2 than non-IMV patients (33 days, IQR 26-46.75, vs 18 days, IQR 16-46.75, respectively, $p<0.01$ ). Median duration of hospitalisation was 9 days (IQR 6-15.5) for non-IMV and 49.5 days (IQR 36.8-82.5) for IMV patients.

Conclusions Our results indicate a short duration of symptoms before admission as a risk factor for severe disease that merits further investigation and different viral load kinetics in severely affected patients. Median duration of hospitalisation of IMV patients was longer than described for acute respiratory distress syndrome unrelated to COVID-19.
\end{abstract}

Keywords Severe acute respiratory syndrome coronavirus 2 (SARS-CoV-2) · Coronavirus disease 2019 (COVID-19) . Viral concentration $\cdot$ COVID-19 nucleic acid testing $\cdot$ Respiratory distress syndrome $\cdot$ Mechanical ventilation $\cdot$ Artificial respiration $\cdot$ Prospective study $\cdot$ Symptom assessment

Victor M. Corman, Florian Kurth have contributed equally.

The members of the Pa-COVID Study Group are mentioned in "Acknowledgements".

Florian Kurth

florian.kurth@charite.de

Extended author information available on the last page of the article

\section{Introduction}

The ongoing severe acute respiratory syndrome coronavirus 2 (SARS-CoV-2) pandemic places an unprecedented burden on healthcare systems worldwide. Host factors predictive of severe clinical course and adverse outcome in patients with coronavirus disease 2019 (COVID-19) include older age, male gender, and pre-existing chronic comorbidities [1-6]. Several risk scores containing clinical characteristics, laboratory assessments, and biomarkers have been proposed for improved patient management and resource allocation $[5,7]$. 
Reported proportions of hospitalised patients requiring invasive mechanical ventilation (IMV) vary considerably between $2.3 \%$ [8] and 23.6\% [2]. In-hospital case fatality rates of $20-30 \%$ have been described in China, Germany, Italy, the UK, and the US [1, 6, 9-11]. In Germany, shortages of inpatient beds and intensive care unit (ICU) capacity were largely avoided during the first pandemic wave, contributing to a comparatively low overall case fatality rate $[1,12]$.

Here, we report clinical characteristics, laboratory and virological parameters, clinical course, and outcome of 168 COVID-19 patients included in a prospective observational cohort study conducted at Charité-Universitätsmedizin Berlin, Germany. The study was designed for deep clinical, molecular, and immunological phenotyping of COVID-19 [13-17].

The data reflect the situation in a tertiary care referral centre for the treatment of patients with acute respiratory distress syndrome (ARDS), including veno-venous extracorporeal membrane oxygenation (vvECMO) therapy, and an associated certified weaning centre during the first months of the COVID-19 pandemic, before treatment with dexamethasone became standard of care [18]. Specific aims of this work were to identify risk factors associated with need for IMV, to analyse viral kinetics in patients with and without IMV, and to provide a comprehensive description of clinical course and outcome.

\section{Methods}

\section{Study cohort and data collection}

Data collection was performed within the Pa-COVID-19 study, a prospective observational cohort study conducted at Charité-Universitätsmedizin Berlin, as described [13]. Adult patients admitted between March 1st and June 30th, 2020, with PCR-confirmed SARS-CoV-2 infection were included if patients or their legal representatives gave informed consent. We recorded epidemiological and demographic data, medical history, history of present illness, symptoms, clinical course, treatment, and outcomes upon enrolment and longitudinally during hospitalisation. The study was approved by the ethics committee of Charite-Universitätsmedizin Berlin (EA2/066/20), conducted according to the Declaration of Helsinki and Good Clinical Practice principles (ICH 1996) and is registered in the German and WHO international clinical trials registry (DRKS00021688).

The primary objective of this first analysis of the PaCOVID-19 cohort was to identify risk factors and virological and laboratory parameters associated with need for IMV. Comorbidities were classified using the Charlson comorbidity Index (CCI) [19]. ARDS was defined according to the Berlin definition of ARDS [20]. Sequential Organ Failure Assessment (SOFA) score [21] was calculated from data recorded in the ICU data management system. The following predefined events were assessed in all patients: (1) sepsis (defined according to sepsis-3 criteria [22], (2) venous thromboembolic events (VTE; pulmonary embolism or deep vein thrombosis), (3) neurologic events (haemorrhagic/ischaemic stroke, delirium, intensive care unitacquired weakness, ICUAW), epileptic seizure, meningitis and encephalitis). Treatment was unaffected by participation in the study. Patient allocation was performed according to structured regional processes [23] and management of critically ill patients following current guidelines as described $[24,25]$. Duration of symptoms was only analysed for patients with reliable information on symptom onset in the patient chart given by patients themselves or relatives.

All laboratory assessments were carried out in accredited laboratories at Charité- Universitätsmedizin Berlin. SARS$\mathrm{CoV}-2$ viral concentration was measured in respiratory samples (naso- or oropharyngeal swabs) by real-time RT-PCR [26]. Viral concentration is given as $\log _{10}$ genome copies per swab or initial $1 \mathrm{~mL}$ sampling buffer.

\section{Statistical analyses}

Distribution of continuous variables was summarised by median and interquartile range (IQR) values or mean and standard deviation (SD), as appropriate. The differences of continuous variables between groups were examined by Welch's $t$ test or, in absence of normal distribution, by Mann-Whitney $U$ test. Categorical variables were compared using Chi-square tests. For all analyses, complete cases were used for the respective evaluation.

We conducted a multiple logistic regression with "need for invasive mechanical ventilation" as a binary dependent variable and age, BMI, hypertension, diabetes, and time between symptom onset and admission to hospital as independent variables. The covariates were chosen taking into account current evidence, results from univariate testing, and sample size. We performed univariate tests regarding all available patient factors and association with organ support treatment, complications, and outcome. Continuous variables were treated as follows: age was categorized in accordance with other reports on patients with COVID-19 [1], BMI and CCI were dichotomized at the median. Patients with therapy limitations (Do Not Intubate (DNI) or Do Not Resuscitate (DNR) orders) at the respective time point were excluded for comparison between non-IMV and IMV patients, and for analyses of course-of-organ support and mortality. Non-survivors were excluded from comparison between short- ( $<15$ days) or long-term ( $\geq 15$ days) IMV. For analysis of SOFA score, scores were extracted from electronic patient charts and the highest score per day was 
included for calculation of means. The neurological component of the SOFA score was not taken into consideration due to patient sedation and incomplete documentation during daily discontinuation of sedation. Patients who died or were transferred to other centres were excluded from calculation of length of hospital stay. For analyses of routine laboratory parameters within $72 \mathrm{~h}$ of first admission, first-available parameters were included.

We compared viral concentration between non-IMV and IMV patients, and regressed viral concentration on the duration from symptom onset to admission using both the first positive RT-PCR result and the RT-PCR with the highest viral concentration. For the calculation of viral concentration decline, we estimated the slope parameter from a linear regression of at least four viral concentration measurements over time for each patient. If available, the first of at least two final negative RT-PCR results was included, in which case the viral concentration of the negative RT-PCR was set to 2.0 in accordance with the RT-PCR limit of detection and sample dilution factor of $\sim 20[26,27]$. We calculated shedding duration as the time from symptom onset to the date of the first of at least two final negative RT-PCR results.

Analyses were conducted with R (version 3.6.1), JMP (version 14.2.0), and statsmodels (version 0.12.0) in Python 3.7.9. A $p$ value $<0.05$ indicates statistical significance, although all results have to be considered as nonconfirmatory. For this reason, no adjustment for multiple testing was done.

\section{Results}

\section{Baseline characteristics}

Between March 1st and June 30th 2020, a total of 347 adult patients with COVID-19 were hospitalised at Charité-Universitätsmedizin Berlin. This analysis includes 168 adult patients who consented to participation in the prospective observational study (Fig. 1). Sixty-five per cent $(110 / 168)$ were directly admitted to our centre, whereas $29.8 \%$ (50/168) were referred due to ARDS or other conditions requiring tertiary care. Four per cent (7/168) were hospitalised for other reasons and coincidentally diagnosed with SARS-CoV-2 infection during routine screening, and one patient $(0.6 \%)$ was admitted due to a late complication of COVID-19.

Baseline characteristics are shown in Table 1. Median patient age was 61 years (IQR 49.3-72), and 66.1\% (111/168) were male. Median CCI was 3 (IQR 1-4). Most prevalent comorbidities were hypertension (53.6\%, $90 / 168)$, diabetes $(19.6 \%, 33 / 168)$, and chronic pulmonary disease $(16.7 \%, 28 / 168)$. Median time from symptom onset until diagnosis was 4 days (IQR 1-7), and from symptom onset until admission to hospital was 6 days (IQR 3-10).

\section{ARDS and organ support treatment}

Fifty-two per cent (88/168) of patients developed ARDS. One of them was already dependent on long-term

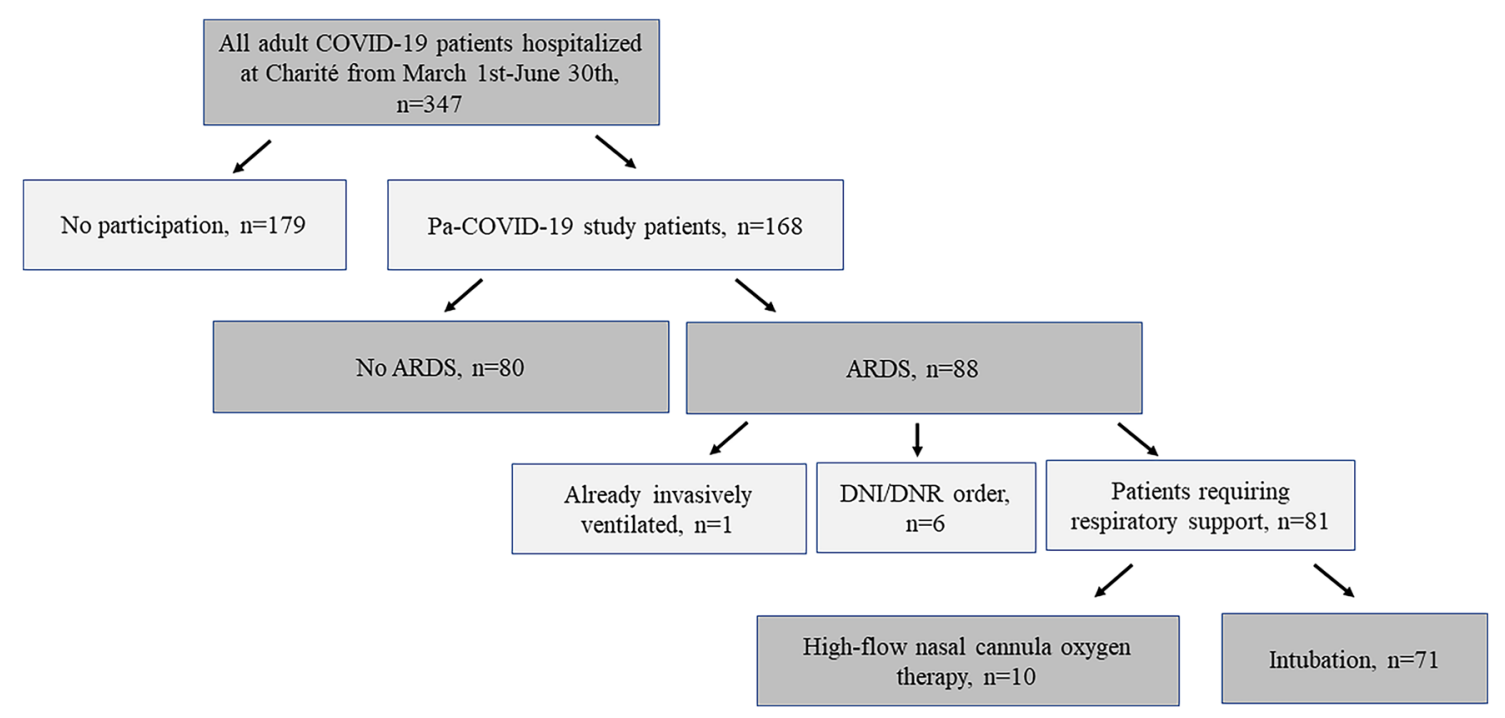

Fig. 1 Study cohort flowchart. A total of 347 adult patients were hospitalised with COVID-19 during the study period from March 1st until June 30th at Charité-Universitätsmedizin Berlin. Of these, 168 patients could be enrolled in the prospective observational study, whereas 179 denied. Among the included patients, 88 had acute res- piratory distress syndrome (ARDS). One patient with ARDS was already invasively ventilated and six of them had DNI/DNR (do not intubate/do not resuscitate) orders in place, resulting in 81 patients requiring respiratory support. Of those, 71 patients were intubated and ten required only high-flow nasal cannula oxygen therapy 
Table 1 Baseline patient characteristics, unadjusted and adjusted odds ratios and 95\% confidence intervals for need of mechanical ventilation

\begin{tabular}{|c|c|c|c|c|c|}
\hline & All patients & Non-IMV & IMV & $\begin{array}{l}\text { Unadjusted OR }(95 \% \\
\mathrm{CI}) ; p \text { value Chi-square } \\
\text { test }\end{array}$ & $\begin{array}{l}\text { Adjusted OR }(95 \% \mathrm{CI}) \\
p \text { value }\end{array}$ \\
\hline $\begin{array}{l}\text { Total number of } \\
\text { patients }\end{array}$ & 168 & $55.9 \%, 90 / 161$ & $44.1 \%, 71 / 161$ & & \\
\hline $\begin{array}{l}\text { Age in years (median, } \\
\text { (IQR)) }\end{array}$ & $61(49.3-72)$ & $59(42-72)$ & $62(54-72)$ & & \\
\hline $18-59$ & $46.4 \%, 78 / 168$ & $54.4 \%, 49 / 90$ & $40.8 \%, 29 / 71$ & Reference group & Reference group \\
\hline $60-69$ & $21.4 \%, 36 / 168$ & $15.6 \%, 14 / 90$ & $31.0 \%, 22 / 71$ & $2.66(1.18-5.89) ; 0.02$ & 4.33 (1.07-20.10); 0.05 \\
\hline $70-79$ & $20.8 \%, 35 / 168$ & $21.1 \%, 19 / 90$ & $19.7 \%, 14 / 71$ & $1.24(0.54-2.85) ; 0.60$ & 0.55 (0.14-1.91); 0.36 \\
\hline$\geq 80$ & $11.3 \%, 19 / 168$ & $8.9 \%, 8 / 90$ & $8.5 \%, 6 / 71$ & $1.26(0.40-4.02) ; 0.69$ & $0.26(0.04-1.54) ; 0.15$ \\
\hline \multicolumn{6}{|l|}{ Gender } \\
\hline Female & $33.9 \%, 57 / 168$ & $38.9 \%, 35 / 90$ & $29.6 \%, 21 / 71$ & Reference group & \\
\hline Male & $66.1 \%, 111 / 168$ & $61.1 \%, 55 / 90$ & $70.4 \%, 50 / 71$ & 1.51 (0.78-2.94); 0.22 & \\
\hline $\begin{array}{l}\text { BMI }\left(\mathrm{kg} / \mathrm{m}^{2}, \text { median, }\right. \\
\quad(\mathrm{IQR}), \text { available } \mathrm{n})\end{array}$ & $\begin{array}{l}27.8(24.6- \\
31.4), \mathrm{n}=156\end{array}$ & $\begin{array}{l}26.9(23.4-30.5), \\
n=81\end{array}$ & $\begin{array}{l}29.06(25.68- \\
33.83) \\
n=69\end{array}$ & & \\
\hline$\geq 30 \mathrm{~kg} / \mathrm{m}^{2}$ & $33.3 \%, 52 / 156$ & $28.4 \%, 23 / 81$ & $39.1 \%, 27 / 69$ & $1.62(0.81-3.21) ; 0.16$ & 1.27 (0.46-3.47); 0.63 \\
\hline \multicolumn{6}{|l|}{ Major comorbidities } \\
\hline CCI median, (IQR) & $3(1-4)$ & $2(0-4)$ & $3(1-4)$ & & \\
\hline$<3$ & $49.4 \%, 83 / 168$ & $60.0 \%, 54 / 90$ & $40.8 \%, 29 / 71$ & Reference group & \\
\hline$\geq 3$ & $50.6 \%, 85 / 168$ & $40.0 \%, 36 / 90$ & $59.2 \%, 42 / 71$ & 2.17 (1.15-4.09), 0.02 & \\
\hline Hypertension & $53.6 \%, 90 / 168$ & $42.2 \%, 38 / 90$ & $63.4 \%, 45 / 71$ & $\begin{array}{l}2.37(1.25- \\
4.49) ;<0.01\end{array}$ & $5.55(2.00-16.82) ;<0.01$ \\
\hline Diabetes & $19.6 \%, 33 / 168$ & $13.3 \%, 12 / 90$ & $23.9 \%, 17 / 71$ & $2.05(0.90-4.63) ; 0.08$ & 1.5 (0.42-5.49); 0.53 \\
\hline $\begin{array}{l}\text { Chronic pulmonary } \\
\text { disease }\end{array}$ & $16.7 \%, 28 / 168$ & $13.3 \%, 12 / 90$ & $21.1 \%, 15 / 71$ & $1.74(0.77-4.00) ; 0.19$ & \\
\hline $\begin{array}{l}\text { Chronic kidney } \\
\text { disease }\end{array}$ & $13.7 \%, 23 / 168$ & $15.6 \%, 14 / 90$ & $8.5 \%, 6 / 71$ & $0.50(0.18-1.38) ; 0.17$ & \\
\hline $\begin{array}{l}\text { Disorder of lipid } \\
\text { metabolism }\end{array}$ & $13.7 \%, 23 / 168$ & $15.6 \%, 14 / 90$ & $9.9 \%, 7 / 71$ & $0.79(0.30-2.10) ; 0.63$ & \\
\hline Cardiac arrhythmia & $13.7 \%, 23 / 168$ & $13.3 \%, 12 / 90$ & $12.7 \%, 9 / 71$ & 0.94 (0.37-2.83); 0.90 & \\
\hline $\begin{array}{l}\text { Chronic myocardial } \\
\text { infarction }\end{array}$ & $7.7 \%, 13 / 168$ & $3.3 \%, 3 / 90$ & $12.7 \%, 9 / 71$ & $4.21(1.09-16.18), 0.03$ & \\
\hline $\begin{array}{l}\text { Congestive heart } \\
\text { failure }\end{array}$ & $5.4 \%, 9 / 168$ & $4.4 \%, 4 / 90$ & $5.6 \%, 4 / 71$ & $1.28(0.30-5.32) ; 0.73$ & \\
\hline $\begin{array}{l}\text { Chronic neurological } \\
\text { disease }\end{array}$ & $9.5 \%, 16 / 168$ & $6.7 \%, 6 / 90$ & $9.9 \%, 7 / 71$ & $1.81(0.58-5.69) ; 0.31$ & \\
\hline $\begin{array}{l}\text { Total number of } \\
\text { substances as con- } \\
\text { comitant medication, } \\
\text { median (IQR), avail- } \\
\text { able } n\end{array}$ & $2(1-3) n=143$ & $2(0-3) n=89$ & $2(1-4) n=54$ & & \\
\hline ARB & $20.2 \%, 29 / 143$ & $15.7 \%, 14 / 89$ & $24.1 \%, 14 / 58$ & 1.77 (0.77-4.09); 0.18 & \\
\hline ACE-i & $18.9 \%, 27 / 143$ & $13.5 \%, 12 / 89$ & $19.0 \%, 11 / 58$ & 1.53 (0.62-3.78); 0.35 & \\
\hline Lipid lowering agents & $18.9 \%, 27 / 143$ & $15.7 \%, 14 / 89$ & $20.7 \%, 12 / 58$ & $1.44(0.61-3.42) ; 0.44$ & \\
\hline $\begin{array}{l}\text { Antibiotics last } \\
90 \text { days }\end{array}$ & $20.2 \%, 29 / 143$ & $19.1 \%, 17 / 89$ & $20.7 \%, 12 / 58$ & 1.09 (0.47-2.53); 0.83 & \\
\hline $\begin{array}{l}\text { Number of symptoms } \\
\text { median (IQR), avail- } \\
\text { able } n\end{array}$ & $3(2-4), n=163$ & $3(2-5), n=85$ & $3(2-4), n=71$ & & \\
\hline Fever & $63.8 \%, 104 / 163$ & $69.4 \%, 59 / 85$ & $63.4 \%, 45 / 71$ & & \\
\hline Dry cough & $53.4 \%, 87 / 163$ & $57.6 \%, 49 / 85$ & $52.1 \%, 37 / 71$ & & \\
\hline Dyspnea & $48.5 \%, 79 / 163$ & $42.4 \%, 36 / 85$ & $53.5 \%, 38 / 71$ & & \\
\hline Fatigue & $27.6 \%, 45 / 163$ & $29.4 \%, 25 / 85$ & $25.4 \%, 18 / 71$ & & \\
\hline
\end{tabular}


Table 1 (continued)

\begin{tabular}{|c|c|c|c|c|c|}
\hline & All patients & Non-IMV & IMV & $\begin{array}{l}\text { Unadjusted OR }(95 \% \\
\mathrm{CI}) ; p \text { value Chi-square } \\
\text { test }\end{array}$ & $\begin{array}{l}\text { Adjusted OR }(95 \% \mathrm{CI}) \\
p \text { value }\end{array}$ \\
\hline Diarrhoea & $12.9 \%, 21 / 163$ & $17.7 \%, 15 / 85$ & $8.5 \%, 6 / 71$ & & \\
\hline Vomitus & $7.4 \%, 12 / 163$ & $9.4 \%, 8 / 85$ & $5.6 \%, 4 / 71$ & & \\
\hline Stomach pain & $4.9 \%, 8 / 163$ & $7.1 \%, 6 / 85$ & $2.8 \%, 2 / 71$ & & \\
\hline $\begin{array}{l}\text { Impaired conscious- } \\
\text { ness }\end{array}$ & $1.8 \%, 3 / 163$ & $1.2 \%, 1 / 85$ & $2.8 \%, 2 / 71$ & & \\
\hline $\begin{array}{l}\text { Olfactory/gustatory } \\
\text { dysfunction }\end{array}$ & $2.5 \%, 4 / 163$ & $2.4 \%, 2 / 85$ & $2.8 \%, 2 / 71$ & & \\
\hline \multicolumn{6}{|l|}{$\begin{array}{l}\text { Indication for admis- } \\
\text { sion }\end{array}$} \\
\hline $\begin{array}{l}\text { Primary COVID-19 } \\
\text { diagnosis }\end{array}$ & $65.5 \%, 110 / 168$ & $87.8 \%, 79 / 90$ & $39.4 \%, 28 / 71$ & & \\
\hline $\begin{array}{l}\text { Referral from other } \\
\text { hospitals }\end{array}$ & $29.8 \%, 50 / 168$ & $5.5 \%, 5 / 91$ & $60.6 \%, 43 / 71$ & & \\
\hline a) ARDS & $17.9 \%, 30 / 168$ & & $42.3 \%, 30 / 71$ & & \\
\hline $\begin{array}{l}\text { b) Other critical medi- } \\
\text { cal condition }\end{array}$ & $3.6 \%, 6 / 168$ & $1.1 \%, 1 / 91$ & $7.0 \%, 5 / 71$ & & \\
\hline $\begin{array}{l}\text { c) Other reason for } \\
\text { referral }\end{array}$ & $8.3 \%, 14 / 168$ & $4.4 \%, 4 / 91$ & $11.3 \%, 8 / 71$ & & \\
\hline $\begin{array}{l}\text { Other primary reason } \\
\text { for admission }\end{array}$ & $4.2 \%, 7 / 168$ & $5.5 \%, 5 / 91$ & $2.8 \%, 2 / 71$ & & \\
\hline Late admission & $0.6 \%, 1 / 168$ & $1.1 \%, 1 / 91$ & - & & \\
\hline $\begin{array}{l}\text { Time between symptom } \\
\text { onset and admission } \\
\text { in days median (IQR), } \\
\text { available } n\end{array}$ & $6(3-10), n=131$ & $8(5-12) n=72$ & $5(2-7) n=55$ & & $1.22(1.10-1.37)^{\mathrm{a}} ;<0.01$ \\
\hline$\leq 5$ days & $41.2 \%, 54 / 131$ & $27.8 \%, 20 / 72$ & $56.4 \%, 31 / 55$ & $\begin{array}{l}3.36,(1.60- \\
7.10),<0.01\end{array}$ & \\
\hline$>5$ days & $58.8 \%, 77 / 131$ & $72.2 \%, 52 / 72$ & $43.6 \%, 24 / 55$ & Reference group & \\
\hline
\end{tabular}

Bold values indicate statistically significant difference between IMV and non-IMV patients

Patients with therapy limitations were excluded from comparison and statistical analysis of IMV versus non-IMV patients. Asymptomatic patients were excluded from analyses of symptom characterisation. Independent variables incorporated into the multiple logistic regression model: Age, BMI, hypertension, diabetes, and length between symptom onset and admission

$I M V$ invasive mechanical ventilation, $O R$ odds ratio, $C I$ confidence interval, $I Q R$ interquartile range, $B M I$ body mass index, $C C I$ Charlson comorbidity index, $A R B$ angiotensin II receptor blockers, $A C E$-i angiotensin-converting enzyme inhibitor, $A R D S$ acute respiratory distress syndrome

${ }^{\mathrm{a}}$ Inverse adjusted OR and confidence interval

intermittent invasive ventilation and six had DNI orders in place. Of the remaining 81 patients with ARDS, $87.6 \%$ (71/81) required IMV whereas $12.3 \%(10 / 81)$ could be managed with HFNC oxygen only (Fig. 1). Median time from hospital admission to intubation was 2 days (IQR 0-4). Among all patients without therapeutic limitations, $44.1 \%(71 / 161)$ required IMV, $9.9 \%$ (16/161) could be treated with HFNC oxygen only, 24.2\% (39/161) required oxygen via nasal prongs, and $22 \%(35 / 161)$ were not in need of supplemental oxygen.

Age between 60 and 69 years as compared to 18 to 59 years (adjusted OR 4.33, 95\% CI 1.07-20.10, $p=0.05$ ) and pre-existing hypertension (adjusted OR 5.55, 95\% CI
$2.00-16.82, p<0.01)$ were independent risk factors for IMV requirement in multivariable analysis. Requirement for IMV increased with shorter duration of symptoms before hospital admission (adjusted OR 1.22 per day less, 95\% CI $1.10-1.37, p<0.01$, Table 1). To account for the possible impact of less accurate information on duration of symptoms in patients transferred from other hospitals, we performed a sensitivity analysis by excluding patients with $>1$ day stay in an external hospital $(n=45)$. This analysis yielded a similar result of increased need of IMV with shorter duration of symptoms (adjusted OR 1.18 95\% CI 1.04-1.35, $p=0.015$ ).

Seventy-nine per cent (56/71) of all intubated patients required long IMV. Need for long IMV was associated 
with a short ( $\leq 1$ day) duration from admission until intubation $(20.0 \%$ (3/15) of patients with short IMV vs $53.6 \%$ (30/56) patients with long IMV, unadjusted OR (uOR) $4.6,95 \%$ CI $1.17-18.16, p=0.02$ ). Other factors associated with long IMV were transferral from other centres (28.6\% (4/14) of patients with short IMV were transferred vs $69.6 \%$ (39/56) of patients with long IMV, uOR 5.73, 95\% CI: $1.58-20.87, p<0.01)$, a higher total mean SOFA score during the second week after initial admission (8.4, 95\% CI 5.83-10.9 in patients with short IMV vs 11.2 , $95 \%$ CI 10.1-12.3, $p=0.04$ in patients with long IMV) as well as differences in SOFA score components (coagulation, hepatic impairment; for details see Supplementary Table 1).

IMV patients had a significantly higher risk of death from COVID-19 compared to non-IMV patients (1.1\% (1/90) of non-IMV patients died vs $29.6 \%$ (21/71) of IMV patients, uOR 37.38, 95\% CI 4.88-286.26, $p<0.01$ ). Sixty-three per cent (44/70) of IMV patients underwent tracheotomy at a median time of 15 days (IQR 12-20) from intubation. Weaning from IMV was successfully concluded in 76.0\% (38/50) of surviving IMV patients after a median of 42 days (IQR 16-66) from intubation. Eighteen per cent $(9 / 50)$ of patients remained dependent on intermittent IMV and 6.0\% (3/50) on long-term oxygen therapy (LTOT) upon discharge or transferral.

Thirty-one per cent (22/71) of all IMV patients required vvECMO (hereafter termed "ECMO") treatment. ECMO was initiated a median of 9 days (IQR 5.3-18.5) from intubation and continued for a median of 18 days (IQR 7.8-35.5). All ECMO patients required haemodialysis, $86.4 \%$ (19/22) underwent tracheotomy, 50\% (11/22) had a VTE, and 50\% (11/22) died. Seventy-five per cent (53/71) of all patients with IMV and all (22/22) patients on ECMO received proning therapy. Details of the subgroup of patients receiving proning therapy have been reported elsewhere [25].

Haemodialysis was initiated in $30.4 \%$ (51/168) of patients, and in $66.2 \%$ (47/71) of patients with IMV. Haemodialysis was initiated after a median of 8 days (IQR 4.5-14 days) following hospital admission and 5 days (IQR 2-8.8 days) after intubation. Thirty-eight per cent (18/47) of IMV patients with haemodialysis died. For details on tracheotomy, ECMO and haemodialysis see Supplementary Table 2.

As no evidence of efficacy of antiviral and anti-inflammatory treatments was available at the time, these were not used systematically and only in a small subgroup of patients of this cohort. Seventeen per cent (29/168) of all patients received corticosteroids in $\geq 40 \mathrm{mg}$ prednisolone equivalent for $\geq 1$ day. For details see Supplementary Table 3 .

\section{Virological and routine laboratory data}

Viral concentration data were available for $166 / 168$ patients. On average, each patient had seven RT-PCR tests (SD: $5.3, \min =1, \max =29$, including positive and negative result) from the day of symptom onset (or 10 days from first admission, if the date of symptom onset was not available) to the end of hospitalisation, with tests performed every 8.4 days on average (SD: 8.8 ). Eighty-six patients had two final negative RT-PCR tests at the end of the disease course. Median first-measured viral concentration differed by $0.68 \log _{10}$ viral copies between IMV and non-IMV patients (5.9, IQR 4.68-7.28 vs $5.22 \log _{10}$ viral copies, IQR 4.49-7.28, respectively; $p=0.12$, Fig. 2a), and median highest viral concentration by $1.19 \log _{10}$ viral copies $(6.7$, IQR 5.35-7.62 vs $5.51 \log _{10}$ viral copies, IQR 4.7-7.62, respectively; $p=0.02$, Fig. 2b). Decline of viral concentration (Supplementary Fig. 1) was significantly slower in IMV versus non-IMV patients $(-0.13, \mathrm{IQR}-0.19$ to -0.08 vs $-0.22 \log _{10}$ viral concentration decrease / day, IQR -0.3 to -0.08 , respectively; $p<0.01$ ) (Fig. 2c, Supplementary Fig. $2 \mathrm{a}-\mathrm{d}$ ). The duration of shedding was significantly longer in IMV patients than in non-IMV patients (median 33, IQR $26-46.75$ vs 18 days, IQR $16-46.75, p<0.01$ ) (Fig. 2 d). We found no association between viral concentration and the duration from symptom onset to admission and no difference in first or in highest viral concentrations in patients requiring long versus short IMV (Supplementary Fig. 3a-d, Supplementary Table 1).

A statistically significant difference between non-IMV and IMV patients was observed in the levels of C-reactive protein (CRP), procalcitonin (PCT), Interleukin-6 (IL-6), lactate dehydrogenase, ferritin, leukocyte count, lymphocyte count, neutrophil-to-lymphocyte ratio, creatinine, urea, aspartate aminotransferase, creatine kinase, $\mathrm{N}$-terminal prohormone of brain natriuretic peptide, and troponin (Supplementary Table 4). The course of 12 routine laboratory parameters over time in non-IMV and IMV patients is shown in Fig. 3.

\section{Complications during treatment}

Eighteen per cent (31/168) of patients developed sepsis. Occurrence of sepsis was associated with organ replacement therapies, but not with patient-related risk factors (Supplementary Table 5). The first sepsis episode occurred after a median of 16 days (IQR 8-21) from hospital admission and 11.5 days (IQR 3-18.3 days) from intubation. In 15/31 (48.4\%) of patients with sepsis, ECMO was initiated during or soon after occurrence of sepsis (median time from occurrence of sepsis and initiation of ECMO, 0 days, IQR $0-6.25$ days). 

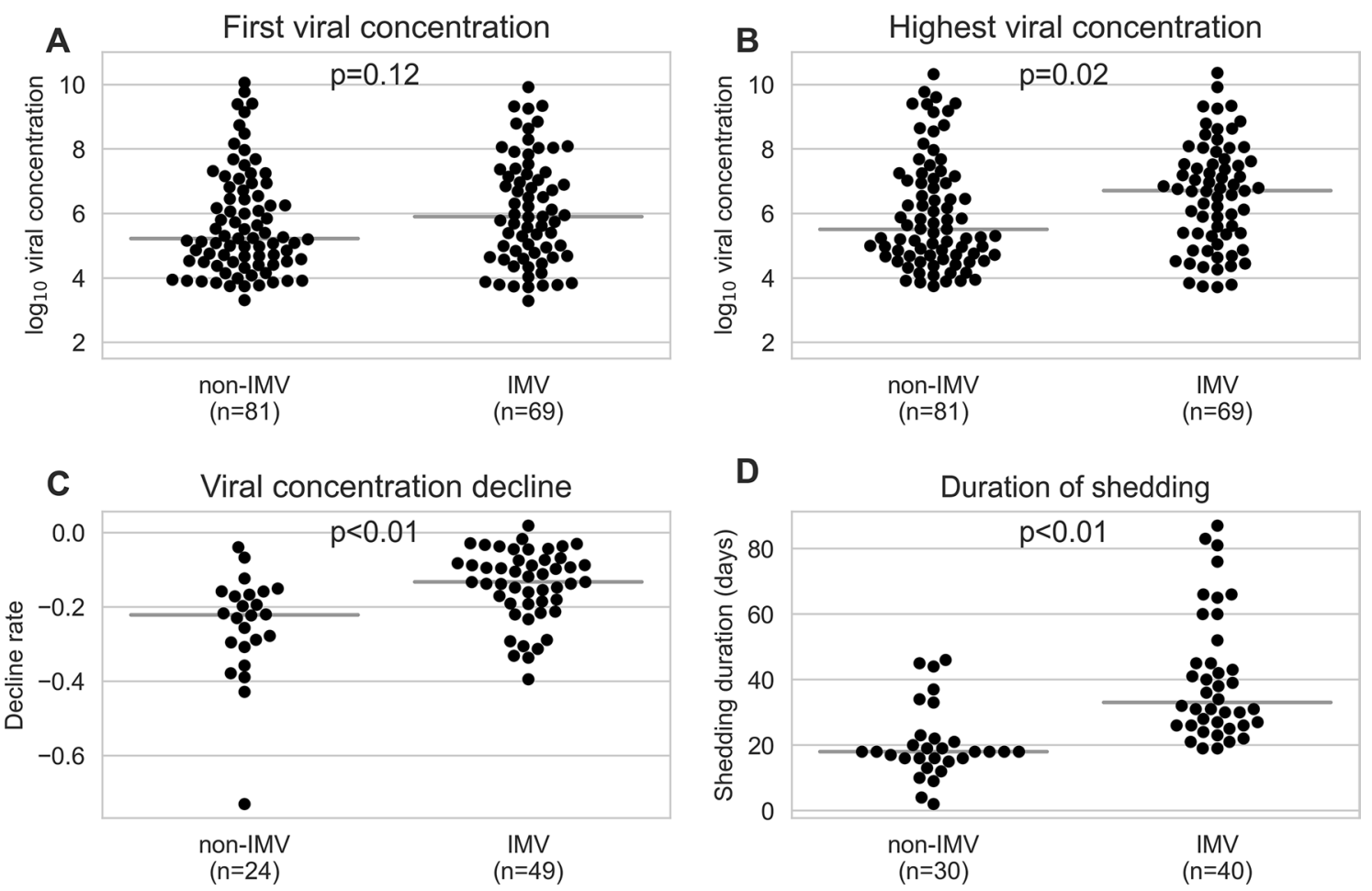

Fig. 2 Comparison of viral concentration between patients with invasive mechanical ventilation (IMV) and those without IMV (nonIMV). a First-measured viral concentration: Median $\log _{10}$ viral concentration and (IQR) are 5.9 (4.68-7.28) for IMV patients and 5.22 (4.49-7.28) for non-IMV patients. b Highest viral concentration: Median $\log _{10}$ viral concentrations and (IQR) are 6.7 (5.35-7.62) for IMV patients and 5.51 (4.7-7.62) for non-IMV patients. $\mathbf{c}$ Differences in the slopes of $\log _{10}$ viral concentration decline rates were estimated using a linear regression of viral concentration from the full disease

Nineteen per cent (32/168) of patients were diagnosed with at least one VTE. Due to evidence for increased risk of thromboembolic events in COVID-19 (36), therapeutic or semitherapeutic anticoagulation was introduced in all critically ill patients from April 2020. A quarter of VTEs (8/32) occurred without anticoagulatory treatment, $18.8 \%(6 / 32)$ under prophylactic anticoagulation, and $46 \%$ (15/32) under therapeutic anticoagulation. In 9.3\% (3/32) of patients, VTE was diagnosed at autopsy and anticoagulation status at onset was unclear.

Twenty-four per cent of patients (41/168) had at least one neurologic event during hospitalisation, including haemorrhagic stroke $(9 / 41,22 \%)$, ischaemic stroke $(3 / 41,7.3 \%)$, delirium $(17 / 41,41.5 \%)$, ICUAW $(17 / 41,41.5 \%)$, and epileptic seizure $(3 / 41,7.3 \%)$. Details of sepsis episodes, VTE and neurologic events are shown in Supplementary table 5.

course of a patient and days since symptom onset $(n=63)$ or admission $(n=10)$ for patients with and without IMV. Only patients with at least four viral concentration measurements were included. d Duration from symptom onset to the first of at least two final negative RT-PCR results for ventilated and non-ventilated patients. Median 33 days (IQR: 26-46.75) for IMV vs 18 days (IQR: 16-46.75) for non-IMV patients, $p<0.01)$ Pairwise comparisons were performed using a Mann-Whitney $U$ test. Grey horizontal lines indicate the median

\section{Outcome}

Median time of hospital stay was 14 days (IQR 7-35) for all, 9 days (IQR 6-15.5) for non-IMV, and 49.5 days (IQR 36.8-82.5) for IMV patients.

Seventeen per cent (29/168) of all patients died. Of all patients without therapy limitations (DNR/DNI), 13.6\% (22/161) died, $8.7 \%$ (14/161) were transferred to other centres, and $77.6 \%(125 / 161)$ were discharged. Median time from first hospitalisation until death was 33 days (IQR 16-98).

In univariate analyses, $\mathrm{CCI} \geq 3$ (uOR $4.35,95 \% \mathrm{CI}$ $1.52-12.45, p<0.01$ ), short duration of symptoms (uOR $6.08,95 \%$ CI $1.88-19.68, p<0.01$ ), occurrence of sepsis (uOR 16.47, 95\% CI 5.85-46.5, $p<0.01$ ), occurrence of VTE (uOR 7.58, 95\% CI 2.88-19.97, $p<0.01$ ) and higher SOFA score during 1st and 2nd week after intubation were associated with death. There was a difference in the median first and highest viral concentration between survivors and non-survivors (6.84, IQR 4.99-7.91 vs 5.38, IQR 4.54-7.91, $p=0.05$; and 7.14, IQR 5.39-7.91 vs 5.86, 

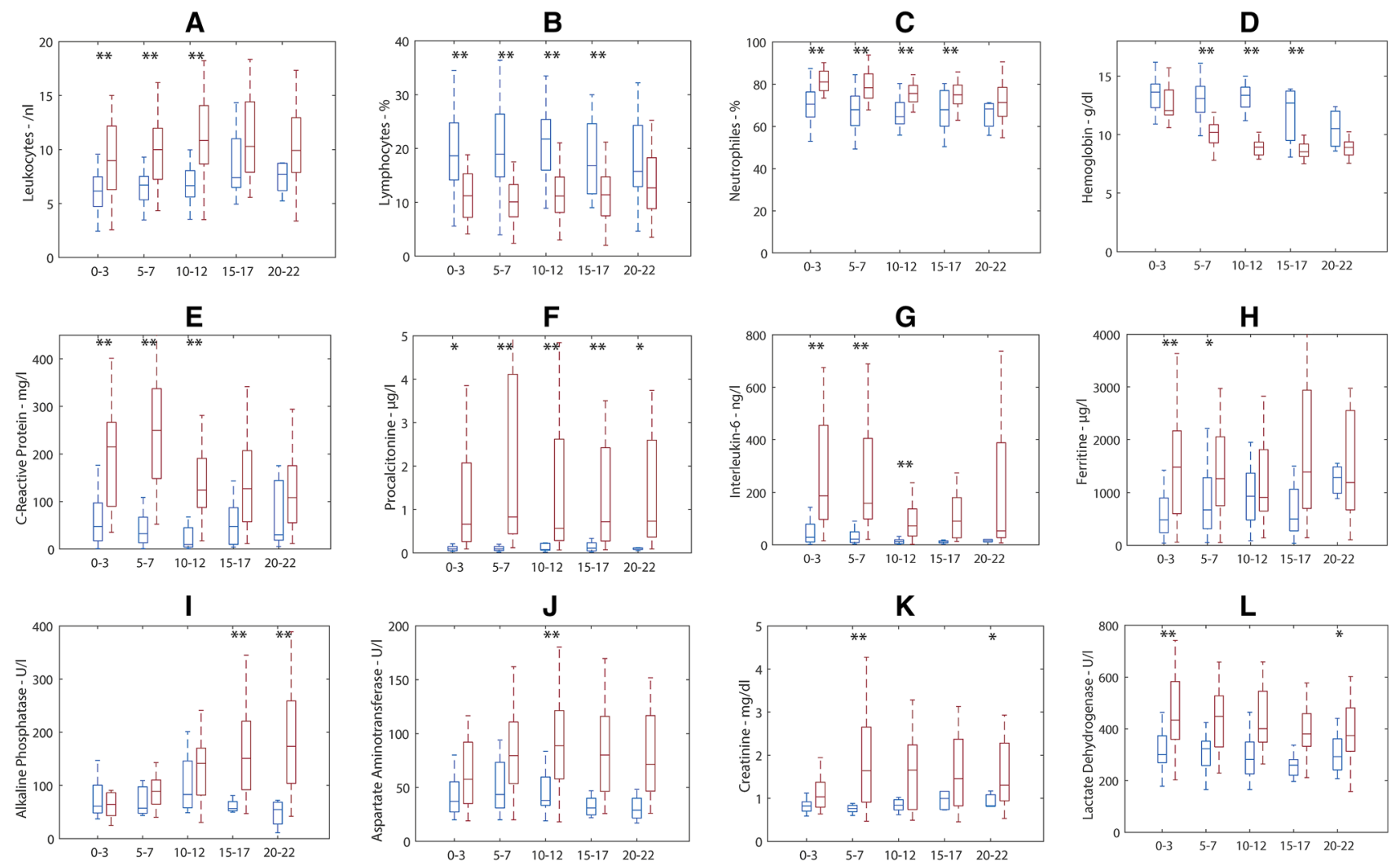

Fig. 3 a-l Comparison of laboratory parameters during the course of disease in IMV (red) versus non-IMV patients (blue). $X$-axis: days post-admission. The boxes and lines are median 25 th and 75 th per-
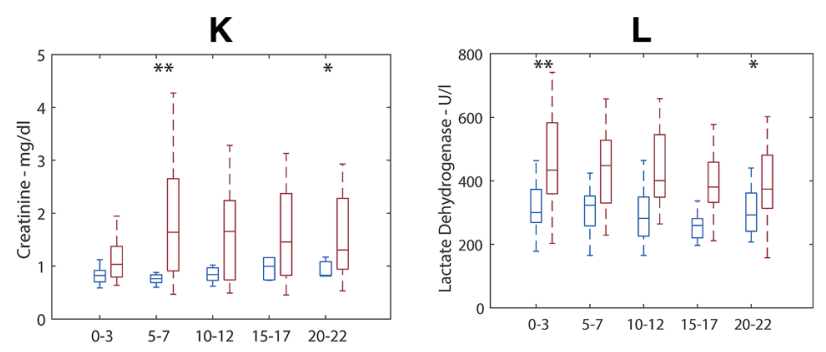

centiles, Whiskers indicate the 1st and 99th percentile. A Welch's $t$ test was used: $* p<0.05, * * p<0.01$

IQR 4.77-7.91, $p=0.04$, respectively) (Supplementary Table 6).

Of all discharged or transferred patients, $6.5 \%(9 / 139)$ still required IMV, $2.9 \%$ (4/139) LTOT, and 1.4\% (2/139) new haemodialysis.

\section{Discussion}

We analysed a detailed clinical and virological dataset from a prospective observational cohort of COVID-19 patients hospitalised in a tertiary, ECMO/ARDS referral and weaning centre in Germany during the first wave of the SARS$\mathrm{CoV}-2$ pandemic, before dexamethasone became standard of care.

We report a short duration of symptoms before clinical deterioration as a risk factor for severe COVID-19. Second, our results indicate that severely ill patients have higher maximal viral concentrations and a slower decline of viral concentration compared to mildly affected patients. Third, we describe a comparatively long duration of inpatient treatment for patients with IMV, largely exceeding that described for non-COVID-19 ARDS patients.

Rapid clinical deterioration-as reflected by short duration of symptoms before hospital admission-is a highly relevant risk factor for both need of IMV in a multivariable risk model and death in univariate analyses in our cohort. A shorter duration of symptoms was not associated with higher initial viral concentration. There was also no difference in initial viral concentration in more severely ill patients, i.e., those requiring IMV, compared to mildly ill patients. Yet, we found a significant increase of inflammatory markers such as CRP, PCT, and IL-6 at presentation and over time in IMV compared to non-IMV patients. Moreover, IMV patients had higher maximal concentrations, a slower decline as well as longer duration of shedding of SARS-CoV-2 compared to non-IMV patients. Higher maximal viral concentrations were also found in patients who died, compared to survivors.

These findings underline that the early inflammatory host response to SARS-CoV-2 determines the course of disease more than pathogen factors such as initial SARSCoV-2 RNA concentration [2, 28, 29]. A short duration of symptoms before admission possibly reflects a rapid increase of the level of inflammation and might serve as an easy to assess prognostic factor for clinical deterioration, a finding that merits further exploration [30]. During the 
further course of COVID-19, severe disease is characterised by the inability to rapidly reduce viral particles. A possible explanation for this phenotype-rapid deterioration after symptom onset, high inflammatory markers, and lack of efficient clearing of viral particles-might be the various kinds of immune dysregulation, as reported by our group and others [15, 31]. Conflicting results have been published regarding the association between clinical severity and viral concentration for SARS-CoV-2 so far [32-36]. This could possibly be explained by a rather unbalanced proportion of mildly and severely affected patients in the respective studies as compared to our cohort [35]. However, it is undetermined whether higher maximal viral concentration and longer duration of shedding are a possible cause or an indicator of more severe organ damage and disease.

Although a remarkable proportion (29.8\%) of patients was transferred to our center due to severe ARDS, and overall $44.1 \%$ needed IMV, we report a comparatively low inhospital mortality of $13.6 \%$ in patients without limitations of therapy. In comparison, Karagiannadis et al. reported inhospital mortality of $22.2 \%$ [1] and Rieg et al. of 23.9\% [37] in cohorts from Germany with $17.2 \%$ [1] and $32.9 \%$ [37] ventilated patients, respectively. Of note, our data show a high median length of hospital stay of 49.5 days for patients requiring IMV. By comparison, the median length of hospital stay for non-COVID ARDS patients was 17 days in a recent global multi-centre prospective study [38]. There is growing evidence that the length of IMV-, ICU-, and inpatient treatment of patients with COVID-19 ARDS exceeds that of patients with ARDS unrelated to COVID-19 [30, 37]. Despite the long median duration of hospital stay, a considerable percentage of patients could not successfully be weaned off the ventilator (18\%), and 6\% required ongoing oxygen therapy following discharge. The mere number of deceased patients therefore depicts the burden of disease of COVID-19 only very incompletely, particularly with respect to long-term morbidity. The prospective approach of our study will allow us to evaluate long-term complications in the aftermath of COVID-19.

Prospective observational studies are often hampered by selection of patients with relatively mild disease courses due to need for informed consent. The high proportion of severely affected patients in this study cohort indicates that this specific selection bias does not apply to our data. On the contrary, it is rather the selection of severely ill patients referred for ARDS management that might have led to a bias. On the other hand, one-fifth of patients was only mildly affected and did not require oxygen therapy, representing a sub-cohort admitted for clinical observation or due to lacking the possibility of self-isolation. Other major limitations of our work are its monocentricity and small sample size.
Our data give a comprehensive description of the clinical course, virological characteristics, organ support treatment, complications, and outcome of a representative cohort of patients in an unrestricted tertiary care healthcare setting with comparatively low mortality. The reported findings will be of value for comparison of clinical courses in the dexamethasone era and for sample size calculation for interventional studies in similar settings.

Supplementary Information The online version contains supplementary material available at https://doi.org/10.1007/s15010-021-01594-w.

Acknowledgements Pa-COVID-19 study group: Linda Jürgens, Malte Kleinschmidt, Sophy Denker, Christoph Ruwwe-Glösenkamp, Bettina Temmesfeld-Wollbrück, Katrin M. Heim, Dirk Schürmann, Andreas Hocke, Bastian Opitz, Belén Millet Pascual-Leone, Rosa C. Schuhmacher, Nadine Olk, David Hillus, Felix Machleidt, Sebastian Albus, Felix Bremer, Jan-Moritz Doehn, Carmen Garcia, Philipp Knape, Philipp M. Krause, Liron Lechtenberg, Yaosi Li, Panagiotis Pergantis, Teresa Ritter, Berna Yedikat, Christian Zobel, Friederike L. Hefele, Ute Kellermann, Mariana Schürmann, Lisa-Marie Wackernagel, Anne Wetzel, Daniel Grund, Jens K. Haumesser, Johannes Hodes, Johannes Rein, Peter Radünzel, Astrid Breitbart, Sergej Münzenberg, Dominik Soll, Tamar Zhamurashvili, Ralf-Harto Hübner, Florian Alius, Tim Andermann, Thomas Cronen, Simon Fraumann, Nikolaj Frost, Dominik Geus, Gisele J. Godzick-Njomgang, Anne Herholz, Vera Hermanns, Moritz Hilbrandt, Till Jacobi, Ye-Ji Kim, Elena Madlung, Luise Martin, Nikolai Menner, Agata Mikolajewska, Luisa Mrziglod, Nadine Muller, Michaela Niebank, Eva Pappe, Frieder Pfäfflin, Lennart Pfannkuch, Matthias Raspe, Nicola Reck, Anne Ritter, Jacopo Saccomanno, Laura K. Schmalbrock, Fridolin Steinbeis, Christoph Tabeling, Markus Vogtmann, Susanne Weber, Markus Brack, Matthias Felten, Sein Schmidt, Maria Rönnefarth, Georg Schwanitz, Alexander Krannich, Saskia Zvorc, Uwe D. Behrens, Lucie Kretzler, Linna Li, Isabelle Wirsching, Chantip Dang-Heine, Michael Hummel, Dana Briesemeister, Denise Treue, Martin Möckel, Samuel Knauß, Matthias Endres, Claudia Spies, Steffen Weber-Carstens, Jan M. Kruse, Daniel Zickler, Andreas Edel, Britta Stier, Philipp Enghard, Roland Körner, Kai-Uwe Eckardt, Lucas Elbert, Christopher Neumann, Marius A. Eckart, Thuy N. Pham, Solveig Schönberger, Alexander Wree, Frank Tacke, Josef Mang, Nadia A. de Vries, Marcel Wittenberg, Jana Riecke, Julia Heeschen, Sascha Treskatsch, Stefan Angermair, Phillip van Dijck

Authors contributions Conception and design: CT, FK, CK, VMC, and LES. Methodology: BM, VMC, and TCJ. Investigation: CT, BM, ETH, MM, TL, PT-L, LBJ, LL, MP, MSS, HM-R, AU, VMC, and FK. Formal analysis: CT, BM, ETH, MM, TL, PT-L, LAM-A, LM, PS, SSH, RR, JW, SH, TZ, FB, and TCJ. Writing original draft: CT, BM, ETH, LL, PT-L, PS, LAM-A, and FK. Supervision: CK, NS, TCJ, CD, MW, LES, VMC, and FK. Funding acquisition: CK, CD, LES, and MW. All authors read and approved the final manuscript.

Funding Open Access funding enabled and organized by Projekt DEAL. The Pa-COVID-19 study is supported by grants from the Berlin Institute of Health (BIH). This study was supported by the German Federal Ministry of Education and Research (NaFoUniMedCovid19NUM-NAPKON, NUM-COVIM, FKZ: 01KX2021 and PROVIDFKZ 01KI20160A) to Florian Kurth, Leif E. Sander, Martin Witzenrath, Norber Suttorp, Christian Drosten and Victor M. Corman and PROVID to Stefan Hippenstiel. The work of CD and VMC is supported by the Berlin Institute of Health, Charite-Universitätsmedizin Berlin and by the German Ministry of Health (Konsiliarlabor für Coronaviren). 


\section{Declarations}

Conflict of interest statement Charlotte Thibeault, Barbara Mühlemann, Elisa T. Helbig, Mirja Mittermaier, Tilman Lingscheid, Pinkus Tober-Lau, Lil A. Meyer-Arndt, Leonie Meiners, Sascha S. Haenel, Laure Bosquillon de Jarcy, Lena Lippert, Moritz Pfeiffer, Miriam S. Stegemann, Robert Roehle, Janine Wiebach, Stefan Hippenstiel, Thomas Zoller, Holger Müller-Redetzky, Alexander Uhrig, Christof von Kalle, Norbert Suttorp, Terry C. Jones, Christian Drosten, Leif E. Sander, Victor M. Corman und Florian Kurth have no conflicts of interest to declare. CT reports grants within the frame of the academic program "clinical studies in infectiology" funded by the German Research Foundation (DFG), outside of the submitted work. MM reports grants from the BIH-Charité Digital Clinician Scientist Program funded by the Charité - Universitätsmedizin Berlin, the Berlin Institute of Health (BIH), and the German Research Foundation (DFG), outside the submitted work. FB reports grants from Einstein Foundation, personal fees from Axon Publishing, grants from Vifor Pharma, personal fees from Elsevier Publishing, grants from Federal Ministry of Health, grants from Berlin Institute of Health, grants from Federal Ministry of Education and Research, outside the submitted work.TCJ is in part funded through NIAID-NIH CEIRS contract HHSN272201400008C. MW reports grants from Deutsche Forschungsgemeinschaft, grants from Bundesministerium für Bildung und Forschung, grants from Deutsche Gesellschaft für Pneumologie, grants from European Respiratory Society, grants from Marie Curie Foundation, grants from Else Kröner Fresenius Stiftung, grants from Capnetz Stiftung, International Max Planck Research School, grants and personal fees from Actelion, grants and personal fees from Bayer Health Care, grants and personal fees from Biotest, grants and personal fees from Boehringer Ingelheim, grants and personal fees from Noxxon, grants and personal fees from Pantherna, grants from Quark Pharma, grants and personal fees from Silence Therapeutics, grants from Takeda Pharma, grants and personal fees from Vaxxilon, personal fees from Aptarion, personal fees from Astra Zeneca, personal fees from Berlin Chemie, personal fees from Chiesi, personal fees from Glaxo Smith Kline, personal fees from Novartis, personal fees from Sinoxa, personal fees from Teva, outside the submitted work

Ethics approval Approval was obtained from the ethics committee of Charité Universitätsmedizin Berlin. The procedures used in this study adhere to the tenets of the Declaration of Helsinki.

Consent to participate Informed consent was obtained from all individual participants or legal representatives included in the study.

Open Access This article is licensed under a Creative Commons Attribution 4.0 International License, which permits use, sharing, adaptation, distribution and reproduction in any medium or format, as long as you give appropriate credit to the original author(s) and the source, provide a link to the Creative Commons licence, and indicate if changes were made. The images or other third party material in this article are included in the article's Creative Commons licence, unless indicated otherwise in a credit line to the material. If material is not included in the article's Creative Commons licence and your intended use is not permitted by statutory regulation or exceeds the permitted use, you will need to obtain permission directly from the copyright holder. To view a copy of this licence, visit http://creativecommons.org/licenses/by/4.0/.

\section{References}

1. Karagiannidis C, Mostert C, Hentschker C, Voshaar T, Malzahn $\mathrm{J}$, Schillinger $\mathrm{G}$, et al. Case characteristics, resource use, and outcomes of 10021 patients with COVID-19 admitted to 920 German hospitals: an observational study. Lancet Respir Med. 2020;8(9):853-62.

2. Petrilli CM, Jones SA, Yang J, Rajagopalan H, O'Donnell L, Chernyak Y, et al. Factors associated with hospital admission and critical illness among 5279 people with coronavirus disease 2019 in New York City: prospective cohort study. BMJ. 2020;369:m1966.

3. Deng G, Yin M, Chen X, Zeng F. Clinical determinants for fatality of 44,672 patients with COVID-19. Crit Care. 2020;24(1):179.

4. Williamson EJ, Walker AJ, Bhaskaran K, Bacon S, Bates C, Morton CE, et al. Factors associated with COVID-19-related death using OpenSAFELY. Nature. 2020;584(7821):430-6.

5. Knight SR, Ho A, Pius R, Buchan I, Carson G, Drake TM, et al. Risk stratification of patients admitted to hospital with covid19 using the ISARIC WHO Clinical Characterisation Protocol: development and validation of the 4C Mortality Score. BMJ. 2020;370:m3339.

6. Docherty AB, Harrison EM, Green CA, Hardwick HE, Pius R, Norman L, et al. Features of 20133 UK patients in hospital with covid-19 using the ISARIC WHO Clinical Characterisation Protocol: prospective observational cohort study. BMJ. 2020;369:m1985.

7. Liu S, Yao N, Qiu Y, He C. Predictive performance of SOFA and qSOFA for in-hospital mortality in severe novel coronavirus disease. Am J Emerg Med. 2020;38(10):2074-80.

8. Guan W-J, Ni Z-Y, Hu Y, Liang W-H, Ou C-Q, He J-X, et al. Clinical characteristics of coronavirus disease 2019 in China. N Engl J Med. 2020;382(18):1708-20.

9. Zhou F, Yu T, Du R, Fan G, Liu Y, Liu Z, et al. Clinical course and risk factors for mortality of adult inpatients with COVID19 in Wuhan, China: a retrospective cohort study. The Lancet. 2020;395(10229):1054-62.

10. Grasselli G, Zangrillo A, Zanella A, Antonelli M, Cabrini L, Castelli A, et al. Baseline characteristics and outcomes of 1591 patients infected with SARS-CoV-2 admitted to ICUs of the Lombardy Region. Italy JAMA. 2020;323(16):1574-81.

11. Richardson S, Hirsch JS, Narasimhan M, Crawford JM, McGinn T, Davidson KW, et al. Presenting characteristics, comorbidities, and outcomes among 5700 patients hospitalized with COVID19 in the New York City Area. JAMA. 2020;323(20):2052-9.

12. Bauer J, Brüggmann D, Klingelhöfer D, Maier W, Schwettmann L, Weiss DJ, et al. Access to intensive care in 14 European countries: a spatial analysis of intensive care need and capacity in the light of COVID-19. Intensive Care Med. 2020;46(11):2026-34.

13. Kurth F, Roennefarth M, Thibeault C, Corman VM, MullerRedetzky H, Mittermaier M, et al. Studying the pathophysiology of coronavirus disease 2019: a protocol for the Berlin prospective COVID-19 patient cohort (Pa-COVID-19). Infection. 2020;48(4):619-26.

14. Messner CB, Demichev V, Wendisch D, Michalick L, White $\mathrm{M}$, Freiwald A, et al. Ultra-high-throughput clinical proteomics reveals classifiers of COVID-19 infection. Cell Systems. 2020;11(1):11-24.e4.

15. Schulte-Schrepping J, Reusch N, Paclik D, Baßler K, Schlickeiser S, Zhang B, et al. Severe COVID-19 Is marked by a dysregulated myeloid cell compartment. Cell. 2020;182(6):141940.e23. 
16. Braun J, Loyal L, Frentsch M, Wendisch D, Georg P, Kurth F, et al. SARS-CoV-2-reactive T cells in healthy donors and patients with COVID-19. Nature. 2020;587(7833):270-4.

17. Kreye J, Reincke SM, Kornau H-C, Sánchez-Sendin E, Corman VM, Liu H, et al. A therapeutic non-self-reactive SARS-CoV-2 antibody protects from lung pathology in a COVID-19 Hamster model. Cell. 2020;183(4):1058-69.e19.

18. Group RC. Dexamethasone in Hospitalized Patients with Covid19. New Engl J Med. 2020;384(8):693-704.

19. Charlson ME, Pompei P, Ales KL, MacKenzie CR. A new method of classifying prognostic comorbidity in longitudinal studies: development and validation. J Chronic Dis. 1987;40(5):373-83.

20. Ranieri VM, Rubenfeld GD, Thompson BT, Ferguson ND, Caldwell E, Fan E, et al. Acute respiratory distress syndrome: the Berlin Definition. JAMA. 2012;307(23):2526-33.

21. Vincent JL, Moreno R, Takala J, Willatts S, De Mendonca A, Bruining H, et al. The SOFA (Sepsis-related Organ Failure Assessment) score to describe organ dysfunction/failure. On behalf of the Working Group on Sepsis-Related Problems of the European Society of Intensive Care Medicine. Intensive Care Med. 1996;22(7):707-10.

22. Singer M, Deutschman CS, Seymour CW, Shankar-Hari M, Annane D, Bauer M, et al. The Third International Consensus Definitions for Sepsis and Septic Shock (Sepsis-3). JAMA. 2016;315(8):801-10.

23. Wiesner B, Bachmann M, Blum TG, Forchheim S, Geiseler $\mathrm{J}$, Kassin A, et al. Responsibilities of weaning centers during the COVID-19 pandemic outbreak-recommendations for the assignment of icu capacities in COVID-19 Patients as shown by the Berlin-Brandenburg POST-SAVE-Model. Pneumologie. 2020;74(6):358-65.

24. Kluge S, Janssens U, Welte T, Weber-Carstens S, Schälte G, Salzberger B, et al. Recommendations for treatment of critically ill patients with COVID-19. Der Anaesthesist. 2020.

25. Mittermaier M, Pickerodt P, Kurth F, de Jarcy LB, Uhrig A, Garcia $\mathrm{C}$, et al. Evaluation of PEEP and prone positioning in early COVID-19 ARDS. EClinicalMedicine. 2020;28:100579.

26. Corman VM, Landt O, Kaiser M, Molenkamp R, Meijer A, Chu DK, et al. Detection of 2019 novel coronavirus (2019-nCoV) by real-time RT-PCR. Euro Surveill. 2020;25(3):2000045.

27. Wölfel R, Corman VM, Guggemos W, Seilmaier M, Zange S, Müller MA, et al. Virological assessment of hospitalized patients with COVID-2019. Nature. 2020;581(7809):465-9.

28. Wu X, Liu L, Jiao J, Yang L, Zhu B, Li X. Characterisation of clinical, laboratory and imaging factors related to mild vs. severe covid-19 infection: a systematic review and meta-analysis. Ann Med. 2020;52(7):334-44.

29. Khinda J, Janjua NZ, Cheng S, van den Heuvel ER, Bhatti P, Darvishian M. Association between markers of immune response at hospital admission and COVID-19 disease severity and mortality: a meta-analysis and meta-regression. J Med Virol. 2021;93(2):1078-98.

30. Schmidt M, Hajage D, Demoule A, Pham T, Combes A, Dres $\mathrm{M}$, et al. Clinical characteristics and day-90 outcomes of 4244 critically ill adults with COVID-19: a prospective cohort study. Intensive Care Med. 2021;47(1):60-73.

31. Lucas C, Wong P, Klein J, Castro TBR, Silva J, Sundaram M, et al. Longitudinal analyses reveal immunological misfiring in severe COVID-19. Nature. 2020;584(7821):463-9.

32. To KK-W, Tsang OT-Y, Leung W-S, Tam AR, Wu T-C, Lung DC, et al. Temporal profiles of viral load in posterior oropharyngeal saliva samples and serum antibody responses during infection by SARS-CoV-2: an observational cohort study. Lancet Infect Dis. 2020;20(5):565-74.

33. Magleby R, Westblade LF, Trzebucki A, Simon MS, Rajan M, Park J, et al. Impact of severe acute respiratory syndrome coronavirus 2 viral load on risk of intubation and mortality among hospitalized patients with coronavirus disease 2019. Clin Infect Dis. 2020:ciaa851.

34. Liu Y, Yan L-M, Wan L, Xiang T-X, Le A, Liu J-M, et al. Viral dynamics in mild and severe cases of COVID-19. Lancet Infect Dis. 2020;20(6):656-7.

35. He X, Lau EHY, Wu P, Deng X, Wang J, Hao X, et al. Temporal dynamics in viral shedding and transmissibility of COVID-19. Nat Med. 2020;26(5):672-5.

36. Cevik M, Tate M, Lloyd O, Maraolo AE, Schafers J, Ho A. SARSCoV-2, SARS-CoV, and MERS-CoV viral load dynamics, duration of viral shedding, and infectiousness: a systematic review and meta-analysis. Lancet Microbe. 2021;2(1):e13-22.

37. Rieg S, von Cube M, Kalbhenn J, Utzolino S, Pernice K, Bechet L, et al. COVID-19 in-hospital mortality and mode of death in a dynamic and non-restricted tertiary care model in Germany. PLoS ONE. 2020;15(11):e0242127.

38. Bellani G, Laffey JG, Pham T, Fan E, Brochard L, Esteban A, et al. Epidemiology, patterns of care, and mortality for patients with acute respiratory distress syndrome in intensive care units in 50 countries. JAMA. 2016;315(8):788-800.

\section{Authors and Affiliations}

\section{Charlotte Thibeault ${ }^{1}$ - Barbara Mühlemann ${ }^{2,3}$ - Elisa T. Helbig ${ }^{1}$ Mirja Mittermaier ${ }^{1,4} \cdot$ Tilman Lingscheid $^{1}$. Pinkus Tober-Lau ${ }^{1}$ - Lil A. Meyer-Arndt ${ }^{5,6}$ - Leonie Meiners ${ }^{2,3}$. Paula Stubbemann ${ }^{1}$ - Sascha S. Haenel ${ }^{1}$. Laure Bosquillon de Jarcy ${ }^{1,2,3}$. Lena Lippert ${ }^{1}$ - Moritz Pfeiffer ${ }^{1}$ - Miriam S. Stegemann ${ }^{1} \cdot$ Robert Roehle $^{4,7}$. Janine Wiebach ${ }^{4,7}$. Stefan Hippenstiel ${ }^{1}$. Thomas Zoller ${ }^{1}$. Holger Müller-Redetzky ${ }^{1}$. Alexander Uhrig ${ }^{1}$. Felix Balzer ${ }^{8}$. Christof von Kalle ${ }^{4}$. Norbert Suttorp ${ }^{1,9} \cdot$ Terry C. Jones $^{2,3,10}$. Christian Drosten ${ }^{2,3}$. Martin Witzenrath $^{1,9} \cdot$ Leif E. Sander ${ }^{1} \cdot$ Pa-COVID Study Group · Victor M. Corman ${ }^{2,3}$ • Florian Kurth ${ }^{1,11,12}$ (B)}

1 Department of Infectious Diseases and Respiratory Medicine Berlin, Charité-Universitätsmedizin Berlin, Augustenburger Platz 1, 13353 Berlin, Germany

2 Institute of Virology, Charité-Universitätsmedizin Berlin, Charitéplatz 1, 10117 Berlin, Germany
3 German Centre for Infection Research (DZIF), Associated Partner Site at Charité - Universitätsmedizin Berlin, Charitéplatz 1, 10117 Berlin, Germany

4 Berlin Institute of Health at Charité - Universitätsmedizin Berlin, Charitéplatz 1, 10117 Berlin, Germany

5 Department of Neurology, Charité-Universitätsmedizin Berlin, Charitéplatz 1, 10117 Berlin, Germany 
6 Experimental and Clinical Research Center, Max Delbrück Center for Molecular Medicine, 13125 Berlin, Germany

7 Institute of Medical Biometrics and Clinical Epidemiology, Charité-Universitätsmedizin Berlin, Charitéplatz 1, 10117 Berlin, Germany

8 Department of Anesthesiology and Operative Intensive Care Medicine, Charité-Universitätsmedizin Berlin, Augustenburger Platz 1, 13353 Berlin, Germany

9 German Centre for Lung Research (DZL), Aulweg 130, 35392 Gießen, Germany
10 Centre for Pathogen Evolution, Department of Zoology, University of Cambridge, Downing St., Cambridge CB2 3EJ, UK

11 Department of Tropical Medicine, Bernhard Nocht Institute for Tropical Medicine, Hamburg, Germany

12 Department of Medicine I, University Medical Centre Hamburg-Eppendorf, 20359 Hamburg, Germany 